\title{
Probabilistic analysis of deformed mode of engineering constructions' soil-cement grounds
}

\author{
Yuriy Vynnykov ${ }^{1 *}$, Olena Voskobiinyk $^{1}$, Maksym Kharchenko $^{1}$, and Valentyn Marchenko ${ }^{1}$ \\ ${ }^{1}$ Poltava National Technical Yuri Kondratyuk University, Department of Civil Engineering, \\ Pershotravnevyi Avenue, 24, Poltava, 36011, Ukraine
}

\begin{abstract}
The results of the analysis of probabilistic methods that are used to assess the deformed state of the foundations of engineering structures are presented. A finite element analysis of the stress-strain state of the "man made soil ground - foundation - structure" system was carried out. A method for probabilistic calculation using the finite element method is proposed. On a real example, the level of reliability of a design decision based on a deterministic calculation is estimated by probabilistic calculation. On the basis of the statistic data obtained by imitational modeling, the probability of failure and no-failure operation of the structure regarding the absolute value of settlement and regarding the value of tilt against the reinforcement ratio of soft soil grounds settlements was determined. The probability of failure regarding the value of tilt against the reinforcement ratio was taken ( 15 to $25 \%$ ), which is $0.03-0.05$.
\end{abstract}

\section{Introduction}

The standard approaches to calculations of soil grounds of the structures and foundations are based on limit states principle. For such calculations, the average values of soil characteristics and load components are used. However, those parameters have the variable nature. That is why taking into account its variety is carried out by the instrumentality of safety factors. By such method one check, the criterions of reaching of one of the limits states: strength or serviceability of structure [1].

The up to date requirements of structure's design on deformable soil grounds provide calculations of the "soil ground - foundation - structure" system taking into account stiffness and strength of soil ground, a stiffness of a whole structure and its separate construction elements [2-4].

To consider the variable character of stated system's component it is necessary to consider the soil ground and the structure like a united (integrated) tridimensional stochastic system and development of methods of its calculation. In this case, the loads and influences (including geological processes), mechanical properties of structure's and ground's elements will become the main factors. The states factors have variable character. That is why for determination of the «soil ground - foundation - structure» system's reliability one need to use probabilistic approach considering the variable nature of values and processes, which influence on it.

\footnotetext{
*Corresponding author: vynnykov@hotmail.com
} 


\section{Analysis of resent research and publications}

There is a line of scientific works devoted to probabilistic nature of loads and influences. It is known that one cannot determine exact values of loads on constructions due to their variable nature.

In addition, the stochastic nature of such characteristics as geometrical parameters of the structure, physical and mechanical properties of its materials was determined $[1,5,6]$. The statistic parameters of stochastic values of material properties one can find in scientific literature and building standards. The spreading of values of those parameters is influenced by construction works execution quality and construction exploitation quality.

The physical and mechanical properties of soils have stochastic nature due to the variety of its staff and composition, the influence on it geological processes, the polydispersity, the polyphasic and polyminerality the character of internal bonds, the value of loads etc. These properties typically change over time due to geological processes. Characteristics of manmade grounds of foundations have similar stochastic nature [7-16].

Due to the number of factors, which influence values of soil characteristics, the statistic parameters and distribution laws of those values were not studied sufficiently. In addition, the limited number of the samples for soil properties determination during investigations was a complication factor.

Thus, we saw that spreading of soil characteristics values is considerable. For reducing this irregularity uses engineering methods for soil improvement (soil compaction, reinforcement, cementation etc.) Due to the number of factors, which influence system serviceability, it is perspective to use finite element method (FEM) for probabilistic analysis of the "soil ground - foundation - structure" system.

\section{Establishing of the objective and tasks of the study}

The main objective of this study is the reliability evaluation of the "man-made ground foundation - construction" system by FEM using the probabilistic approach.

The tasks for achievement of that objective include: 1) analysis of experimental statistic data of physical and mechanical properties of soils and man-made grounds; 2) analysis of world-wide progress in probabilistic calculations of foundation grounds; 3) FE analysis of deformed mode of man-made ground with the use of elastic-plastic soil model and imitational simulation.

\section{The main part of the study}

As statistic parameters of stochastic values of soil properties accepted mean value $\mu_{x}$, standard deviation $\sigma_{x}$, a coefficient of variation $v_{x}$ and distribution law (probability density function). Statistic parameters of properties of natural soils according to various authors are given in Table 1.

One of the effective methods for soil improvement is a construction of soil-cement grounds. By the researching, performed under the direction of prof. M. Zotsenko were determinate the statistic parameters of soil-cement properties distribution. The coefficient of variation is 10 to $15 \%$.

Based on the experience of different researchers, it was determinate, that distribution law of permanent vertical loads and temporary loads is normal with coefficients of variation $10 \%$ and $50 \%$, respectively [12], and horizontal variable loads described by Gumbel law with a coefficient of variation $25 \%$. Findings of researches of stochastic nature of loads on foundations are given in table 2 . 
For reliability evaluation of constructions developed a row of methods such as: linearization, O.S. Lychov's enumerative technique, V.P. Chyrkov's method of numerical integration, method of statistical testing well known as Monte Carlo Simulation (MCS), Response Surface Method (RSM), Point Estimate Method (FO-PEM \& A-PEM) and First Order Reliability Method (A-FORM) etc. [9, 11-15, 19-24].

Table 1. Coefficient of variation $v_{x}(\mathrm{COV})$ values and distribution laws of natural soil characteristics.

\begin{tabular}{|c|c|c|c|c|}
\hline \multirow[t]{2}{*}{ Characteristic } & \multicolumn{4}{|c|}{ Distribution function (probability density function) } \\
\hline & Sand & Sandy loam & Loam & Clay \\
\hline Moisture content, $w$ & $\frac{30-50 / 4.4-49 /-}{\text { Normal }}$ & $\frac{10-30 / 6.2-}{\frac{27.7 / 8-30}{\text { Normal }}}$ & $\frac{8-28 / 3.8-15 / 8-30}{\text { Normal }}$ & $\begin{array}{c}4-25 / 12.65 / 8 \\
\underline{30} \\
\text { Normal }\end{array}$ \\
\hline $\begin{array}{c}\text { Porosity coefficient, } \\
e\end{array}$ & $\frac{3-13 / 1.1-6.7 /-}{\text { Normal }}$ & $\frac{6-12 / 2.3-16.5 /-}{\text { Normal }}$ & $\frac{6-25 / 3.5-14.2 /-}{\text { Normal }}$ & $\frac{3-22 / 19.3 /-}{\text { Normal }}$ \\
\hline Density, $\rho$ & $\frac{2-7.5 / 0.5-}{\frac{3.2 /<10}{\text { Normal }}}$ & $\frac{2-4.5 / 0.5-}{\frac{2.5 /<10}{\text { Normal }}}$ & $\frac{2.5-7.5 / 0.8-}{\underline{3.7 /<10}}$ & $\frac{2-6 / 4.3 /<10}{\text { Normal }}$ \\
\hline $\begin{array}{l}\text { Density of soil } \\
\text { particles, } \rho_{s}\end{array}$ & $\frac{-/ 0-0.3 /-}{\text { Normal }}$ & $\frac{-/ 0.2-0.65 /-}{\text { Normal }}$ & $\frac{-/ 0.2-0.6 /-}{\text { Normal }}$ & $\frac{-/ 0.8 /-}{\text { Normal }}$ \\
\hline Plasticity index, $I_{\mathrm{p}}$ & & $\frac{25-50 /-/ 10-40}{\text { Normal }}$ & $\frac{5-35 /-/ 10-40}{\text { Normal }}$ & $\frac{7-30 /-/ 10-40}{\text { Normal }}$ \\
\hline Plasticity limit, $w_{\mathrm{p}}$ & & $\frac{6-17 /-/ 6-30}{\text { Normal }}$ & $\frac{5-25 /-/ 6-30}{\text { Normal }}$ & $\frac{7-27 /-/ 6-30}{\text { Normal }}$ \\
\hline Fluidity limit, $\mathrm{w}_{\mathrm{L}}$ & & $\frac{5-16 /-/ 6-30}{\text { Normal }}$ & $\frac{5-20 /-/ 6-30}{\text { Normal }}$ & $\frac{5-20 /-/ 6-30}{\text { Normal }}$ \\
\hline Shearing resistance, $\tau$ & $-/-$ & $\frac{9-27 /-/ 10-30}{\text { Lognormal }}$ & $\frac{6-29 /-/ 10-30}{\text { Lognormal }}$ & $\frac{-/-/ 20-50}{\text { Lognormal }}$ \\
\hline Friction angle, $\varphi$ & $\frac{-/-/ 5-15}{\text { Normal }}$ & $-/-/ 5-15$ & $-/-/ 12-56$ & $-/-/ 12-56$ \\
\hline $\begin{array}{l}\text { Stiffness } \\
\text { modulus, } E\end{array}$ & $\frac{-/-/ 15-65}{\text { Lognormal }}$ & $-/-$ & $\frac{15-35 / 18.6-65.4}{\text { Lognormal }}$ & $-/-$ \\
\hline
\end{tabular}

Note: over line data of Ermolaev M.M. and Mikheev V.V. [1] / data of Bukhrov O.K. and Shilin V.G. [1] / data of Phoon K.K and Kulhaw [23]; under line distribution law according to Fenton G.A. [8]

Table 2. Coefficient of variation (COV) values for loads on foundations.

\begin{tabular}{|l|c|}
\hline \multicolumn{1}{|c|}{ Load type } & COV \\
\hline Dead load & 0.1 \\
\hline Variable load (50 years maximum) & 0.25 \\
\hline Snow load (50 years maximum) & 0.26 \\
\hline Wind load (50 years maximum) & 0.37 \\
\hline Earthquake load (50 years maximum, West and East of the USA) & 1.38 \\
\hline
\end{tabular}

Every of those methods are the convenient instrument for solving of particular problem. The main universal methods are MCS, RSM and PEM. They are used for solving of geotechnical problems by FEM. Such approach is implemented in Ansys (USA), Phase $^{2}$ (Canada) and in the special utility for Plaxis (under the direction of S. Baars).

The failure of foundation consist of such components: 1) failure (the ultimate limit state), the stresses under foundation is more than the limit soil resistance $p>p_{u} ; 2$ ) absolute $S>S_{u}$ or different settlements $\Delta S / L>(\Delta S / L)_{u}$ of ground exceeded the limit settlement values (the serviceability limit state). 
The foundation ground failure determination regarding the serviceability limit state is complicated the fact of settlement can be linear $S_{L}$ or nonlinear $S_{p}$.

The probabilistic analysis can be performed by numerical simulation with the use of FEM. There is a row of probabilistic geotechnical problems, which cannot be solved by analytical methods.

In exemplification the allowable irregularity of loading of two silo-type grain-storages, which share one foundation plate on soft soil ground was determinate (Fig. 1). The allowable irregularity means that its value does not exceed the normative limit. For this reason, FE analysis of the deformed mode of soft soil ground of foundation plate of grainstorages, which was improved by soil-cement was performed. In Figure 2, the diagrams of settlements over time according to results of instrumental measurements and simulations are presented.
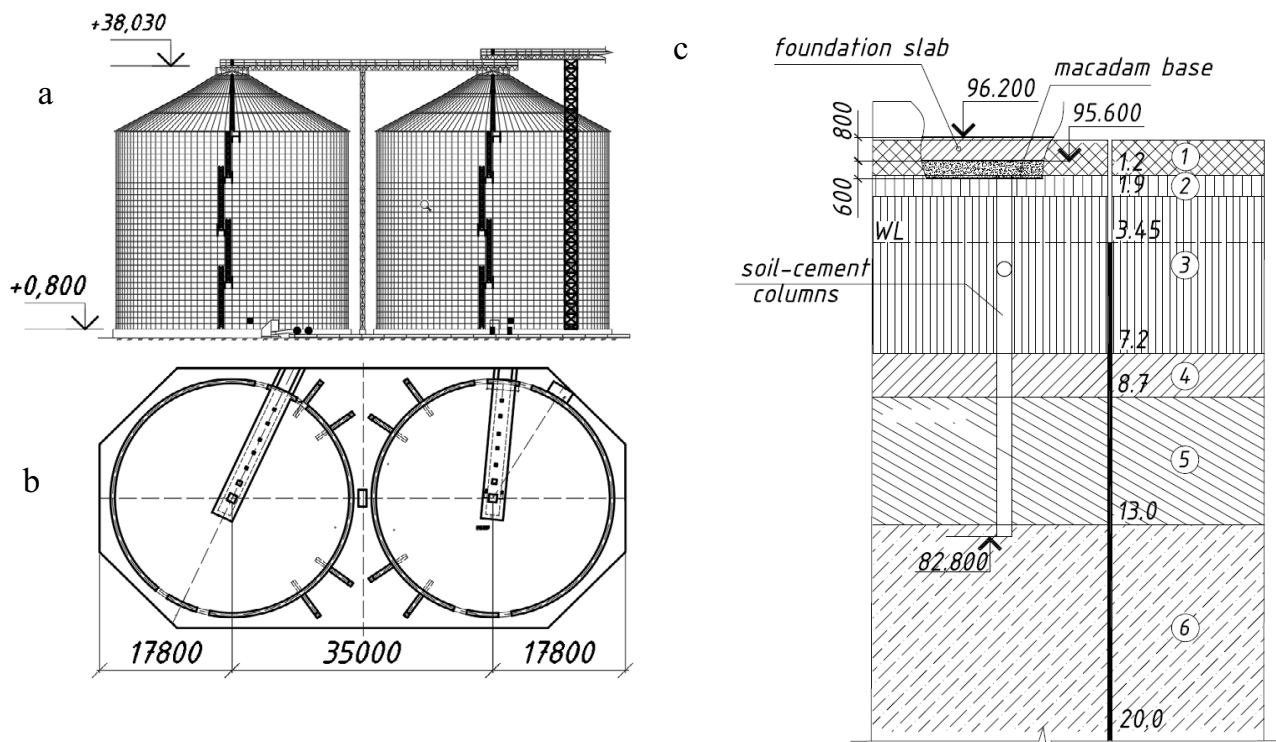

Fig. 1. Overall view of silo-type grain storages with the capacity of $24121 \mathrm{~m}^{3}$ each: $\mathrm{a}-$ front view; $\mathrm{b}-$ plan at the level of $+0.800 ; \mathrm{c}-$ ground profile.

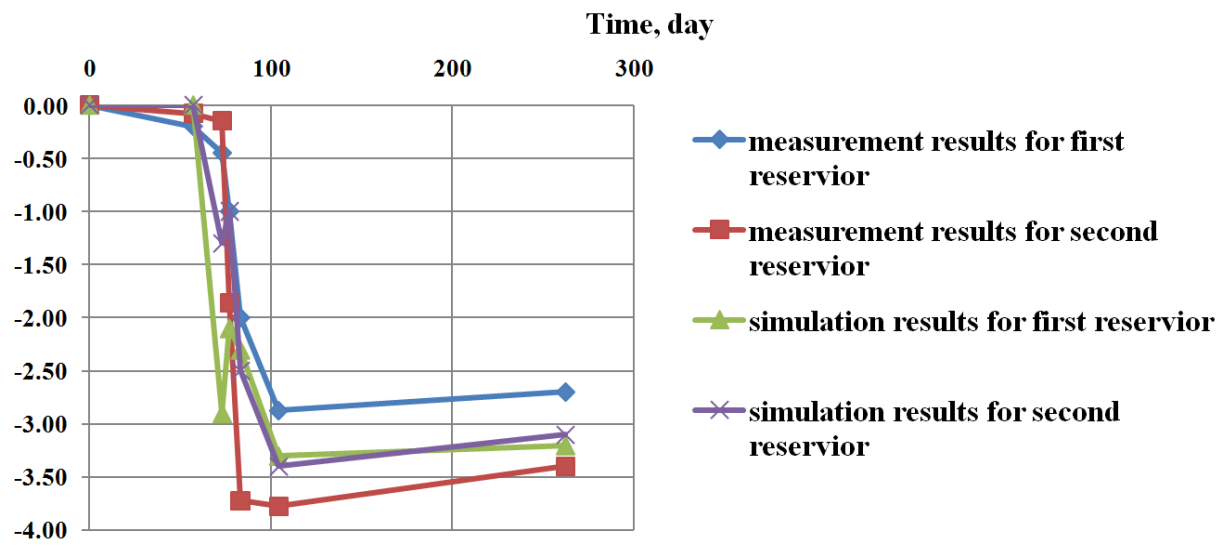

\section{Settlement, sm}

Fig. 2. Diagrams of settlements over time according to results of instrumental measurements and simulations. 
Table 3. Input data for probabilistic analysis of foundation's improved grounds.

\begin{tabular}{|l|c|c|}
\hline \multirow{2}{*}{ Characteristic } & \multirow{2}{*}{ Distribution law } & $\begin{array}{c}\text { Statistic } \\
\text { parameters }\end{array}$ \\
\cline { 3 - 3 } & & COV, $\%$ \\
\hline Stiffness modulus of soil, MPa & lognormal & 15 \\
\hline Stiffness modulus of soil-cement, MPa & normal & 15 \\
\hline Loading of reservoir & normal & 30 \\
\hline
\end{tabular}

It was accepted to improve soil ground under the foundation plate down to $12 \mathrm{~m}$ depth. To ensure required strength and stiffness properties, the ratio of reinforcement of ground was approximately $25 \%$. The diameter of soil-cement columns was $0.5 \mathrm{~m}$ and spacing between them 0.9 and $0.95 \mathrm{~m}$. Statistical parameters of stochastic values of input characteristics are given in table 3. PEM was used to avoid a large amount of iterations during imitational numerical simulation by FEM (Fig. 3). Parameters were changed simultaneously on two levels ( $\mu \pm 3 \sigma$, where $\mu$ - mean value, $\sigma$ - standard deviation): 1) stiffness modulus of soil layers of reinforced ground E; 2) loading of reservoir \#1; 3) loading of reservoir \#2.

The finite element analysis was performed with different combinations of stochastic values and was determine settlements and tilt of foundation plate in the particular stages of silo-type storages exploitation. In the Fig. 4, a 3-D deformed FE mesh of analytical model on one of stages of imitational modeling by PEM is given. The distribution and statistic parameters of the stochastic value of reinforced ground settlements after initial loading and unloading are given in Fig. 5 according to results of an imitational simulation.

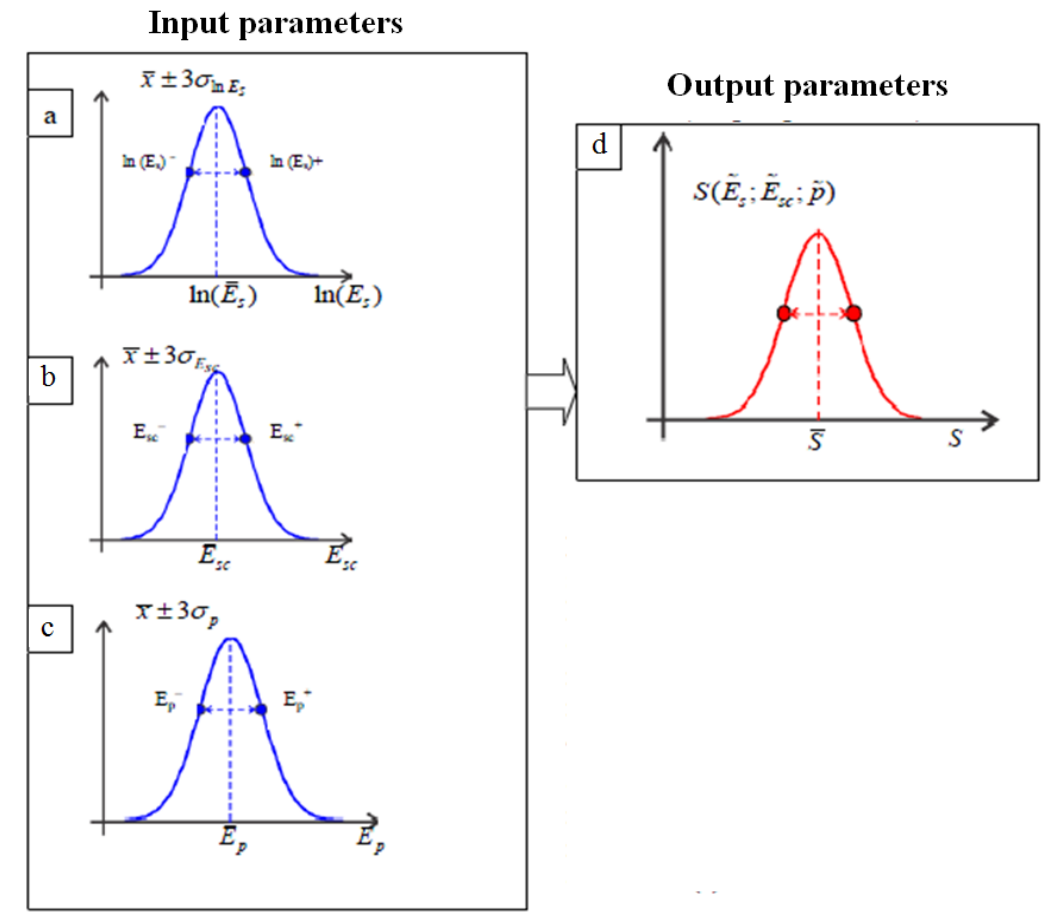

Fig. 3 Scheme of probabilistic analysis by PEM: a - density of distribution of stiffness modulus of soil $E_{s} ; \mathrm{b}$ - density of distribution of stiffness modulus of soil-cement $E_{s c} ; \mathrm{c}$-density of distribution of the pressure to ground $\mathrm{p} ; \mathrm{d}$ - density of distribution of improved ground settlements. 


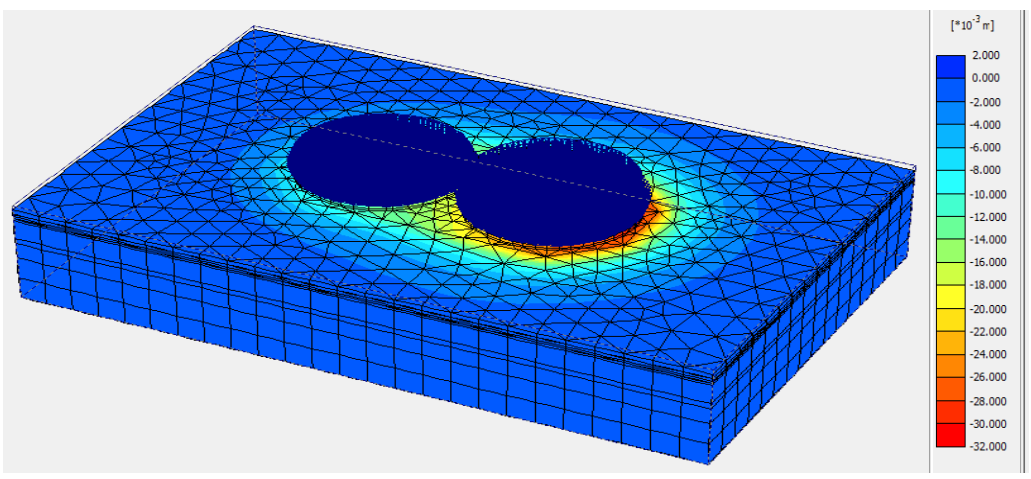

Fig. 4. Deformed 3-D FE mesh of the analytical model of imitational simulation regarding to PEM.

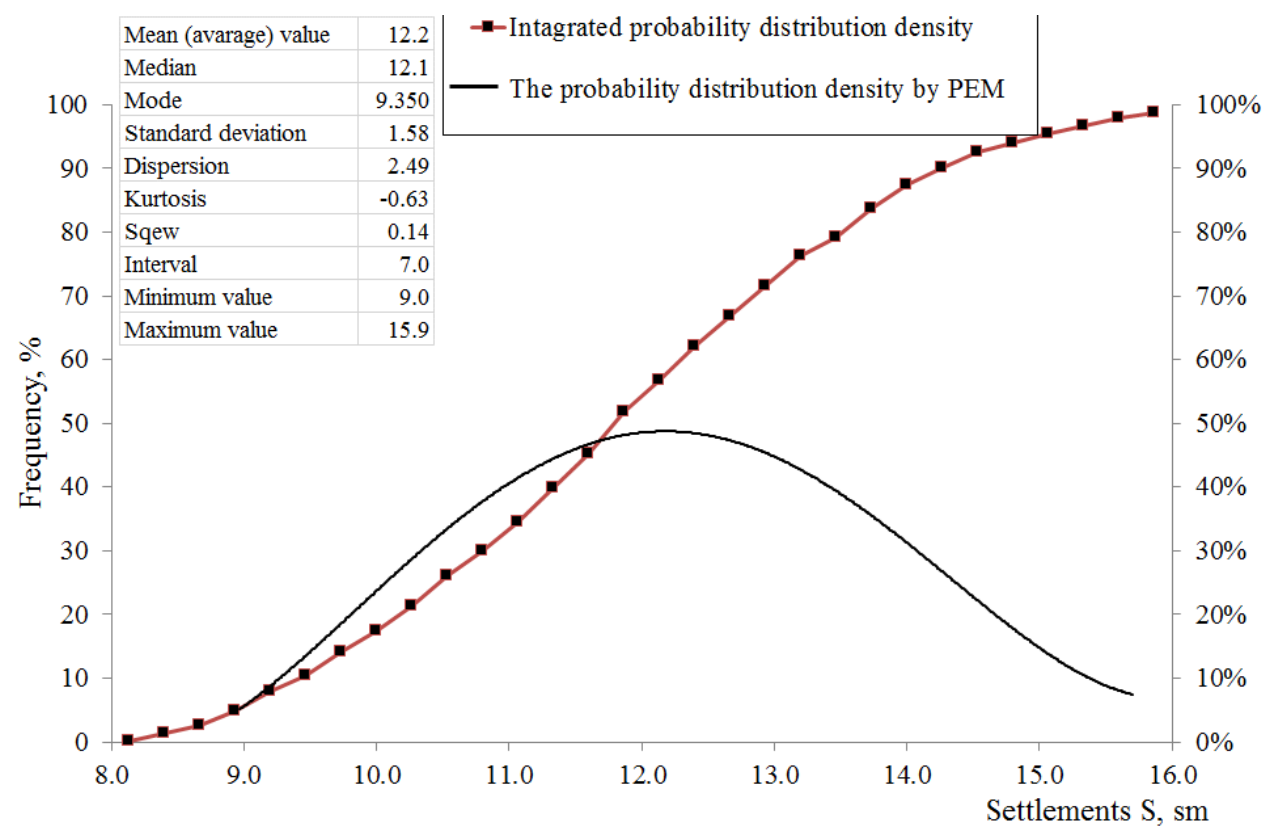

Fig. 5. Distribution of stochastic value of improved soil ground for foundation plate according to results of imitational simulation by FEM.

The distribution and statistic parameters of stochastic values of tilt of the foundation plate are given in the Fig. 6 (the value of tilt was multiplied by 104). During the subsequent loadings of reservoirs, the absolute values of settlements increase and have damped character. In that case, the probability of failure regarding of settlements is not more 0.001 and regarding of tilt -0.07 .

On the basis of the statistic data obtained by imitational modeling, the probability of failure and no-failure operation of the structure regarding the absolute value of settlement (Fig. 7) and regarding the value of tilt against the reinforcement ratio of soft soil grounds settlements was determined. The probability of failure regarding the value of tilt against the reinforcement ratio was taken ( 15 to $25 \%$ ), which is $0.03-0.05$.

According to the results of imitational simulation, the allowable irregularity of loading of reservoirs with shared foundation plate on the improved soil ground is $20 \%$. The probability of structure failure regarding criterion of limit allowable tilt of foundation plate $(i=0.002)$ is less than 0.01 . On the base of imitational simulation by FEM using PEM for 
reliability rate of $p=0.9$ was matched the minimal required reinforced ratio of soil ground by soil-cement columns (it is $19 \%$ ).

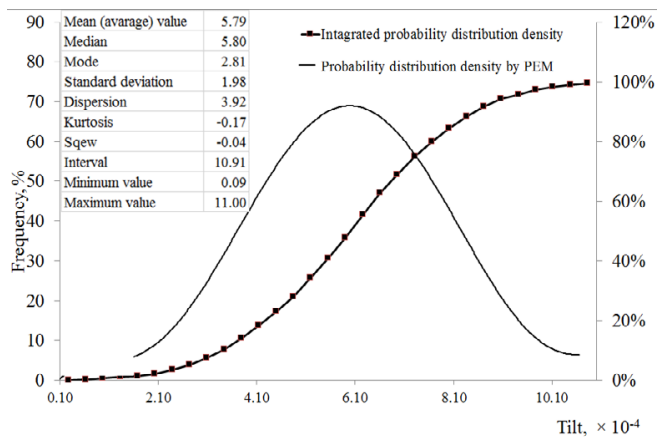

Fig. 6. Distribution of stochastic value of foundation plate tilt according to results of imitational simulation by FEM (the value of tilt was multiplied by $10^{4}$ ).

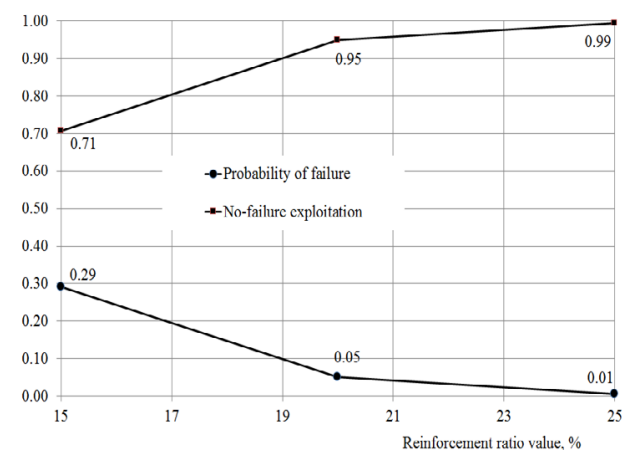

Fig. 7. Probability of failure and no-failure exploitation of structure regarding to criterion of absolute settlement against of reinforcement ratio value.

This problem shows that through the instrumentality of probabilistic approach the required reinforcement ratio of soft soil ground for the ensuring the no-failure exploitation of construction during its life was validated.

\section{Conclusions}

For probabilistic design calculations of the grounds of foundations, the statistic data of stochastic values of physical and mechanical properties of nature soils can be used according to Table 1, loads to soil ground - Table 2, improved grounds by soil-cement columns - Table 3.

Stochastic nature of linear and nonlinear stages of deformation process of soil grounds should be taken into account to determine the reliability of the grounds of foundations regarding criterions of its strength and stiffness.

It is reasonable to use MCS, RSM, and PEM that were approved enough by scientists including authors of this article to determine the reliability of nature and man-made soil grounds of foundations by numerical methods of calculation.

Decisions which allow reaching the required reliability rate should be taken for the benefit of the rational design of the grounds of foundations.

\section{References}

1. A.K. Bugrov, V.H. Shilin, Opredelenie verojatnostnuh haracteristik aktivnogo davlenia grunta metodom Monte-Carlo, Reconstruction of cities and geotechnical construction, 5, 3 (2003)

2. A.V. Perelmuter, Izbrannye problemy nadejnosty, bezopasnosty stroitelnyh construksiy, Moscow (2007)

3. S.F. Pishugin, Nadejnost stalnyh construksiy proizvodstvennyh zdaniy, Poltava (2009)

4. J. Xue, D. Nag, Reliability analysis of shallow foundations subjected to varied inclined loads, Proc. of the $3^{\text {rd }}$ Intern. Symposium on Geotechnical Safety and Risk, Munich, 7 (2011)

5. A.S. Lychev, Nadejnost stroitelnyh construksiy, Moscow (2008) 
6. V.P. Chircov, Pricladnye metody teorii nadejnosty $v$ raschetah stroitelnyh construksiy, Moscow (2006)

7. A.N. Trofimchuk, V.G. Chernyi, G.I. Chernyi, Nadejnost sistem soorujenie - gruntovoe osnovanie $v$ slojnyh injenerno-geologicheskih usloviah, Kyiv (2006)

8. G.A. Fenton, Probabilistic Methods in Geotechnical Engineering, Utah, 96 (1997)

9. A.L. Rechenmacher, Z. Medina-Cetina, R.G. Ghanem, Calibration of heterogeneous, probabilistic soil models, Proc. $16^{\text {th }}$ Intern. Conf. on Soil Mechanics and Geotechnical Engineering, Osaka, 3 (2005)

10. Y. Wang, B. Wang, Study on autocorrelation model and reduction function of variance of soil random field, Proc. of the $1^{\text {st }}$ Intern. Symposium on Geotechnical Safety and Risk, China, Shanghai, 7 (2007)

11. G.B. Beacher, J.T. Cristian, Reliability and statistics in geotechnical Engineering, New York, 619 (2003)

12. A.J. Bond, A procedure for determining the characteristic value of a geotechnical parameter, Proc. of the $3^{\text {rd }}$ Intern. Symposium on Geotechnical Safety and Risk, Germany, Munich, 7 (2011)

13. Y. Honjo, Challenges in Geotechnical Reliability Based Design, Proc. of the $3^{\text {rd }}$ International Symposium on Geotechnical Safety and Risk, Germany, Munich, 6 (2011)

14. C. Pereira \& L. Caldeira, Shallow Foundation Design through Probabilistic and Deterministic, Proc. of the $3^{\text {rd }}$ Intern. Symposium on Geotechnical Safety and Risk, Germany, Munich, 8 (2011)

15.J.Y. Won A probabilistic approach to estimate one dimensional consolidation settlements, Proc. of the 17th Intern. Conf. on Soil Mechanics and Geotechnical Engineering, Egypt, Olexandria, 3 (2009)

16. S. Baars, M.A. Deptula, E. Dembicki, Ph. Gotteland, Adaption of finite element models for probabilistic design, Proc. of the $11^{\text {rd }}$ Baltic Sea Geotechnical Conf. "Geotechnics in Maritime Engineering", Poland, Gdansk, 6 (2007)

17. M. Zotsenko, Y. Vynnykov, M. Kharchenko, Evaluation of failure probability of soil cushions, Proc. of the $3^{\text {rd }}$ Intern. Symposium on Geotechnical Safety and Risk, Germany, Munich, 8 (2011)

18. G. Falsone, N. Impollania, A new approach for the stochastic analysis of finite element modeled structures with uncertain parameters, Computer Methods in Applied Mechanics and Engineering, 191(44), 18 (2002)

19. M. Fredlund, Finite elements stochastic analysis, Proc. of $57^{\text {th }}$ Canadian Geotechanical Conf. and $5^{\text {th }}$ Joint IAH-CGS Conf., Canada, Quebec, 5 (2004)

20. A. Haldar, S. Mahadevan, Reliability Assessment Using Stochastic Finite Elements Analysis, New York, 220 (2000)

21. M. Manjuprasad, C.S. Manohar, Adaptive Random Field Mesh Refinementsin Stochastic Finite Element Reliability Analysis of Structures, CMES, 21 (2007)

22. G.M. Pechl, H.F. Schweiger, Reliability analysis in geotechnics with deterministic finite elements - a comparison of two methods, Proc. of $5^{\text {th }}$ European Conf. on Numerical Methods in Geotechanical Engineering, Paris, 5 (2002)

23. K.K. Phoon, Reliability-based design in geotechnical engineering. Computions and applications, New York (2008)

24. B. Sudret, A. Kiureghian, Stochastic Finite Elements Methods and Reliability. A stateof-the-Art Report, Berkeley, Civil and Environment Engineering University of California (2000) 